\title{
Deep analyses of the associations of a series of biomarkers with insulin resistance, metabolic syndrome, and diabetes risk in nondiabetic middle-aged and elderly individuals: results from a Chinese community-based study
}

This article was published in the following Dove Press journal:

Clinical Interventions in Aging

27 October 2016

Number of times this article has been viewed

\author{
Shihui Fu ${ }^{1,2, *}$ \\ Ping Ping ${ }^{3, *}$ \\ Leiming Luo' \\ Ping $\mathrm{Ye}^{\prime}$ \\ 'Department of Geriatric Cardiology, \\ ${ }^{2}$ Department of Cardiology and \\ Hainan Branch, ${ }^{3}$ Department of \\ Pharmaceutical Care, Chinese People's \\ Liberation Army General Hospital, \\ Beijing, People's Republic of China \\ *These authors contributed equally \\ to this work
}

\begin{abstract}
Objective: The current study was designed to perform deep analyses of the associations of biomarkers, including high-sensitivity C-reactive protein (hs-CRP), N-terminal prohormone of brain natriuretic peptide (NT-proBNP), and homocysteine (Hcy), with insulin resistance (IR), metabolic syndrome (MetS), and diabetes risk and evaluate the abilities of biomarkers to identify IR, MetS, and diabetes risk in Chinese community-dwelling middle-aged and elderly residents.
\end{abstract}

Participants and methods: A total of 396 participants older than 45 years underwent physical examinations and laboratory analyses following standardized protocol.

Results: Serum hs-CRP concentrations were able to identify MetS, Chinese diabetes risk score $(\mathrm{CDRS}) \geq 4$, high-density lipoprotein-cholesterol (HDL-c) $<0.9 / 1.0 \mathrm{mmol} / \mathrm{L}$, and HDL-c $<1.0 / 1.3 \mathrm{mmol} / \mathrm{L}$ ( $P<0.05$ for all). Serum NT-proBNP concentrations were able to identify homeostasis model assessment of IR $>1.5$, CDRS $\geq 4$, overweight, and blood pressure $(\mathrm{BP}) \geq 140 / 90 \mathrm{mmHg}$ ( $P<0.05$ for all). Serum Hcy concentrations were able to identify $\mathrm{CDRS} \geq 4$, general obesity, overweight, and $\mathrm{BP} \geq 140 / 90 \mathrm{mmHg}(P<0.05$ for all $)$. Serum hs-CRP concentrations were independently associated with MetS as well as HDL-c $<1.0 / 1.3 \mathrm{mmol} / \mathrm{L}$ and HDL-c $<0.9 / 1.0 \mathrm{mmol} / \mathrm{L}(P<0.05$ for all). Serum NT-proBNP concentrations were independently associated with $\mathrm{BP} \geq 140 / 90 \mathrm{mmHg}(P<0.05)$. Serum Hcy concentrations were independently associated with CDRS $\geq 4(P<0.05)$.

Conclusion: Serum HDL-c levels were the major determinant of the associations between serum hs-CRP levels and MetS and the key link between inflammation and MetS. There was no other association of these biomarkers with IR, MetS, and diabetes risk after full adjustment.

Keywords: biomarkers, diabetes risk, insulin resistance, metabolic syndrome, middle-aged and elderly

\section{Introduction}

Metabolic syndrome (MetS) is a constellation of interrelated metabolic risk factors that appear to directly promote the development of diabetes and cardiovascular diseases. ${ }^{1}$ Identification of biomarkers associated with MetS and diabetes is desirable to establish screening programs, preventive interventions, and therapeutic strategies most appropriately directed at MetS and diabetes, which can reduce the increased prevalence of MetS and diabetes worldwide and attenuate the morbidity and mortality
Department of Geriatric Cardiology,

Chinese People's Liberation Army General Hospital, Fuxing Road 28, Beijing 100853, People's Republic of China

Tel +86 I0 88626362

Fax +861066876349

Email lleim@sina.com;

yeping301@sina.com 
of diabetes and cardiovascular disease., ${ }^{2,3}$ Although several studies have analyzed the associations of MetS and diabetes risk with biomarkers, including high-sensitivity C-reactive protein (hs-CRP), N-terminal prohormone of brain natriuretic peptide (NT-proBNP), and homocysteine (Hcy), there have been too much controversial results. ${ }^{4-14}$ To our knowledge, a limited amount of information is available regarding these associations in non-Caucasian populations, particularly among Chinese community-dwelling residents. ${ }^{15,16}$

Recent studies have more and more focused on the significant role of insulin resistance (IR) in linking cardiovascular risk factors. ${ }^{17}$ Studies about the associations of IR with biomarkers representing diverse biological roles and pathological phenomena can help us to understand the mechanisms underlying the development of MetS and diabetes. Notably, few studies, especially Chinese community-based studies, concerning the associations of IR with biomarkers, including hs-CRP, NTproBNP, and Hcy, have been conducted, and it is a long way to go for the definite answer. ${ }^{10,18-22}$

Therefore, the aim of the current study was to perform deep analyses of the associations of biomarkers, including hs-CRP, NT-proBNP, and Hcy, with IR, MetS, and diabetes risk and evaluate the abilities of biomarkers to identify IR, MetS, and diabetes risk in Chinese community-dwelling middle-aged and elderly residents.

\section{Participants and methods Study participants and information collection}

The current study was conducted as part of a large health checkup program in Beijing, People's Republic of China, during the period from May 2007 to July 2009. The participants were restricted to the community-dwelling residents of Han origin older than 45 years at the time of health examination. There were a total of 396 participants in the current analysis after excluding 63 participants due to the diagnosis of diabetes. A stratified cluster sampling design was used in this survey. In the first stage of sampling, three districts (Fengtai, Shijingshan, and Daxing) were selected from 18 districts in Beijing. In the second stage of sampling, four communities were selected from these districts. In the third stage of sampling, participants were selected from these communities. The study protocol was approved by the ethics committee of Chinese People's Liberation Army General Hospital (Beijing, People's Republic of China). Each participant provided written informed consent to be included in the study. The participants underwent routine clinical physical examinations, which included measurements of height, weight, waist circumference (WC), and resting blood pressures (BPs). All data for each participant were evaluated by well-trained physicians in Chinese People's Liberation Army General Hospital. Standing height was determined using a wall-mounted measuring tape without shoes. Body weight was determined using a digital scale with the participants lightly clothed and without shoes. Body mass index (BMI) was calculated as the ratio of the weight $(\mathrm{kg})$ to the square of height $\left(\mathrm{m}^{2}\right)$. WC was measured using a soft tape while the subjects stood balanced on both feet, with the feet touching each other and both arms hanging freely. Measurements were taken midway between the lowest rib and the iliac crest. Systolic blood pressure (SBP) and diastolic blood pressure (DBP), measured using a standard mercury sphygmomanometer, were taken at the first and fifth Korotkoff sounds in the seated position after participants rested for at least 5 minutes. Two measurements were performed at 1-minute intervals, and the mean of two readings was used for analyses.

\section{Laboratory analyses}

Blood samples were withdrawn between 8 am and 10 am after an overnight fast of at least 12 hours, routinely stored, and submitted to the central laboratory in the Department of Biochemistry, Chinese People's Liberation Army General Hospital, on the same day. Fasting blood glucose (FBG), triglyceride (TG), low-density lipoprotein-cholesterol (LDL-c), and high-density lipoprotein-cholesterol (HDL-c) were checked by qualified technicians blinded to clinical data using enzymatic assays (Hoffman-La Roche Ltd., Basel, Switzerland) on a fully automatic biochemical analyzer (Cobas c6000; Hoffman-La Roche Ltd.). The participants attending the collection of fasting blood sample subsequently performed the standard oral glucose tolerance test and obtained the postprandial blood glucose (PBG), which was done 2 hours after consumption of 75 g glucose. Concentrations of hs-CRP were determined by an immunoturbidimetric assay using a Dimension RxL Max analyzer (Siemens Healthcare Diagnostics Inc., Munich, Germany). Concentrations of NT-proBNP were measured with an electrochemiluminescence immunoassay (Hoffman-La Roche Ltd.) using an analyzer (Cobas c6000). Concentrations of Hcy were determined by high-performance chromatography with fluorometric detection. Fasting insulin (FINS) levels were determined by DPC kit (DPC cirrus Inc., Los Angeles, CA, USA) on a fully automatic chemiluminescence analyzer (DPC IMMULITE 1000; DPC cirrus Inc.). All assays were performed without knowledge of participants' clinical data. 


\section{Variable definitions}

IR was assessed by the homeostasis model assessment of IR (HOMA-IR) using the following formula: HOMA-IR = FINS $(\mathrm{mIU} / \mathrm{L}) \times \mathrm{FBG}(\mathrm{mmol} / \mathrm{L}) / 22.5{ }^{23}$ According to the worldwide consensus on the definition of MetS recommended by the International Diabetes Federation, ${ }^{24}$ for a person to be defined as having the MetS, he or she must have central obesity plus any two of four additional factors: $\mathrm{TG} \geq 1.7 \mathrm{mmol} / \mathrm{L}$, HDL-c $<1.0 \mathrm{mmol} / \mathrm{L}$ in males and $<1.3 \mathrm{mmol} / \mathrm{L}$ in females (or specific treatment for these lipid abnormalities), $\mathrm{SBP} \geq 130 \mathrm{mmHg}$ or DBP $\geq 85 \mathrm{mmHg}$ (or treatment of previously diagnosed hypertension), and $\mathrm{FBG} \geq 5.6 \mathrm{mmol} / \mathrm{L}$ (or previously diagnosed diabetes). General obesity, overweight, and central obesity were defined as BMI $\geq 28 \mathrm{~kg} / \mathrm{m}^{2}$, $\mathrm{BMI} \geq 24 \mathrm{~kg} / \mathrm{m}^{2}$, and $\mathrm{WC} \geq 85 \mathrm{~cm}$ for men and $\geq 80 \mathrm{~cm}$ for women based on the Guidelines for Preservation and Control of Overweight and Obesity in Chinese Adults, respectively. ${ }^{25}$ More recently, our hospital set up the first risk score of the People's Republic of China identifying individuals who were likely to develop diabetes in the near future, named the Chinese diabetes risk score (CDRS), which consisted of age ( $<66$ : coded $0 ;$ 66-75: coded 1; $\geq 76$ : coded 2), hypertension (coded 1), history of high blood glucose ( $\operatorname{coded} 3)$, BMI $(<24$ : coded $0 ; \geq 24$ : coded 1), high FBG (coded 2), high TG (coded 1), and low HDL-c (coded 2). Hypertension was defined as having the $\mathrm{SBP} \geq 140 \mathrm{mmHg}$, $\mathrm{DBP} \geq 90 \mathrm{mmHg}$, or the use of antihypertensive medications. Diabetes was defined as being present if $\mathrm{FBG}$ was $\geq 7.0 \mathrm{mmol} / \mathrm{L}, \mathrm{PBG}$ was $\geq 11.1 \mathrm{mmol} / \mathrm{L}$, or insulin or oral hypoglycemic medications were used. $\mathrm{FBG} \geq 5.6 \mathrm{mmol} / \mathrm{L}$ was considered as high $\mathrm{FBG}$. $\mathrm{TG} \geq 1.7 \mathrm{mmol} / \mathrm{L}$ was defined as high TG. HDL-c $<0.9 \mathrm{mmol} / \mathrm{L}$ in men or HDL-c $<1.0 \mathrm{mmol} / \mathrm{L}$ in women was considered as low HDL-c. The total score value ranged from 0 to 12, and a cutoff score of 4 indicated optimum sensitivity and specificity for detecting diabetes. ${ }^{26}$

\section{Statistical analyses}

Categorical variables were reported as number with percentage, normally distributed continuous variables as mean with standard deviation, and nonnormally distributed continuous variables as median with interquartile range. Differences between groups were analyzed with chi-squared test for categorical variables, independent $t$-test for normally distributed continuous variables, and Mann-Whitney test for nonnormally distributed continuous variables. Bivariate correlations of biomarkers with each component of MetS and CDRS, MetS component numbers, CDRS, and HOMA-IR were determined using the Pearson's (normal distribution) and Spearman's (abnormal distribution) coefficients. Receiver operating characteristic curves and area under the curve were used to evaluate whether the biomarkers were capable to identify each component of MetS and CDRS, HOMA-IR, MetS, and CDRS. The logistic regression procedures were applied to assess the risk of each component of MetS and CDRS, HOMA-IR, MetS, and CDRS according to biomarkers. All reported $P$-values were two tailed, and confidence intervals were calculated at the $95 \%$ level. All statistical analyses were performed using Statistic Package for the Social Sciences (version 17.0; SPSS Inc., Chicago, IL, USA) software.

\section{Results \\ Baseline characteristics}

For the total population, the median age was 66 years (58-71 years), and 53\% were male, with median hs-CRP, NT-proBNP, and Hcy concentrations of $0.29 \mathrm{mg} / \mathrm{dL}$ (0.17-0.38 mg/dL), $41.42 \mathrm{pg} / \mathrm{mL}(17.34-80.72 \mathrm{pg} / \mathrm{mL})$, and $17.20 \mu \mathrm{mol} / \mathrm{L}(14.10-21.58 \mu \mathrm{mol} / \mathrm{L})$, respectively. The prevalence of MetS and general obesity was 33\% and $21 \%$, respectively. The median level of HOMA-IR was 1.5 (1.0-2.1), and $25 \%$ of participants had CDRS $\geq 4$.

\section{Simple comparisons}

The characteristics of the whole cohort grouped by the levels of HOMA-IR and the presence of MetS are provided in Table 1. The individuals with HOMA-IR $>1.5$ and MetS were more likely to have higher levels of BMI, WC, DBP, FINS, PBG, TG, and hypertension and lower HDL-c levels than others $(P<0.05$ for all). The levels of SBP in the individuals with MetS and the levels of FBG in the individuals with HOMA-IR $>1.5$ were higher than those of others ( $P<0.05$ for all). In spite of no difference in sex ratio between the individuals with and without HOMA-IR $>1.5$ $(P>0.05)$, there were more males with MetS $(P<0.05)$. The levels of LDL-c were similar between the individuals with and without MetS and HOMA-IR $>1.5$ ( $P>0.05$ for all) Both groups were similar with regard to history of high blood glucose ( $P>0.05$ for all). Serum hs-CRP concentrations in the individuals with MetS were higher than those of others $(P<0.05)$, but they were similar between the individuals with and without HOMA-IR $>1.5(P>0.05)$. Serum NT-proBNP concentrations in the individuals with HOMA-IR $>1.5$ were lower than those of others $(P<0.05)$, but they were similar between the individuals with and without MetS $(P>0.05)$. There was no difference in serum Hcy concentrations between the individuals with and without HOMA-IR $>1.5$ and MetS $(P>0.05$ for all). 
Table I Baseline characteristics of entire population according to the levels of HOMA-IR and the presence of MetS

\begin{tabular}{|c|c|c|c|c|c|c|}
\hline Characteristics & $\begin{array}{l}\text { HOMA-IR } \leq 1.5 \\
(\mathrm{n}=198)\end{array}$ & $\begin{array}{l}\text { HOMA-IR }>I .5 \\
(\mathrm{n}=198)\end{array}$ & $P$-value & $\begin{array}{l}\text { Without MetS } \\
(n=293)\end{array}$ & $\begin{array}{l}\text { With MetS } \\
(n=103)\end{array}$ & $P$-value \\
\hline Age (years) & $66(60-72)$ & $65(57-70)$ & 0.041 & $65(57-7 I)$ & $67(60-7 I)$ & 0.105 \\
\hline Males (\%) & $101(5 \mathrm{I} .0)$ & $110(55.6)$ & 0.365 & $152(57.1)$ & $59(45.4)$ & 0.028 \\
\hline BMI $\left(\mathrm{kg} / \mathrm{m}^{2}\right)$ & $23.81(21.66-25.98)$ & $26.7 I(24.66-28.7 I)$ & $<0.001$ & $24.35(22.17-26.42)$ & 27.21 (24.90-28.87) & $<0.00 \mathrm{I}$ \\
\hline$W C(\mathrm{~cm})$ & $84.50(77.75-90.25)$ & $92.00(87.00-97.00)$ & $<0.001$ & $86.00(79.00-91.00)$ & 94 (90-99) & $<0.00 \mathrm{I}$ \\
\hline Hypertension (\%) & $73(36.9)$ & $93(47.0)$ & 0.042 & $92(34.6)$ & $74(56.9)$ & $<0.00 \mathrm{I}$ \\
\hline $\mathrm{SBP}(\mathrm{mmHg})$ & $132(120-144)$ & $134(125-145)$ & 0.055 & $130(|| 8-|4|)$ & $139(130-150)$ & $<0.00 \mathrm{I}$ \\
\hline $\mathrm{DBP}(\mathrm{mmHg})$ & $76(70-84)$ & $80(70-90)$ & 0.003 & $77(70-85)$ & $80(7 \mid-90)$ & 0.003 \\
\hline History of high blood glucose & $9(4.5)$ & II (5.6) & 0.646 & II (4.I) & $9(6.9)$ & 0.234 \\
\hline $\mathrm{FBG}(\mathrm{mmol} / \mathrm{L})$ & $4.60(4.30-4.91)$ & $4.97(4.63-5.35)$ & $<0.001$ & $4.73(4.42-5.12)$ & $4.81(4.42-5.48)$ & 0.081 \\
\hline FINS (mlU/L) & $4.79(3.6 \mathrm{I}-6.02)$ & $9.96(8.35-12.90)$ & $<0.001$ & $6.26(4.29-9.10)$ & $9.09(6.95-12.29)$ & $<0.00 \mathrm{I}$ \\
\hline PBG (mmol/L) & $5.88(4.98-7.12)$ & $6.68(5.55-8.21)$ & $<0.001$ & 6.01 (5.03-7.39) & $7.10(5.72-8.55)$ & $<0.00 \mathrm{I}$ \\
\hline $\mathrm{TG}(\mathrm{mmol} / \mathrm{L})$ & I.27 (0.96-I.7I) & $1.55(1.22-2.07)$ & $<0.001$ & $1.23(0.96-1.57)$ & $1.96(I .49-2.6 \mathrm{I})$ & $<0.001$ \\
\hline HDL-c (mmol/L) & $1.44(1.16-1.73)$ & $1.21(1.04-1.49)$ & $<0.00 \mathrm{I}$ & $1.49(1.24-1.73)$ & $1.07(0.93-1.18)$ & $<0.001$ \\
\hline LDL-c (mmol/L) & $2.91(2.42-3.39)$ & $2.79(2.33-3.26)$ & 0.173 & $2.80(2.33-3.26)$ & $2.91(2.47-3.48)$ & 0.056 \\
\hline hs-CRP (mg/dL) & $0.27(0.15-0.38)$ & $0.30(0.18-0.40)$ & 0.056 & $0.26(0.15-0.36)$ & $0.33(0.22-0.45)$ & $<0.00 \mathrm{I}$ \\
\hline NT-proBNP (pg/mL) & $47.14(20.79-87.20)$ & $35.80(14.93-67.10)$ & 0.004 & $4 I .40(\mid 7.40-78.1 I)$ & $41.74(17.28-86.98)$ & 0.462 \\
\hline Hcy $(\mu \mathrm{mol} / \mathrm{L})$ & $17.20(14.18-21.73)$ & $16.90(\mid 3.90-21.50)$ & 0.709 & $16.90(|3.60-2| .23)$ & $17.85(14.30-22.43)$ & 0.174 \\
\hline
\end{tabular}

Notes: Data presented as median (interquartile range) or $\mathrm{n}(\%)$.

Abbreviations: HOMA-IR, homeostasis model assessment of insulin resistance; MetS, metabolic syndrome; BMI, body mass index; WC, waist circumference; SBP, systolic blood pressure; DBP, diastolic blood pressure; FBG, fasting blood glucose; FINS, fasting insulin; PBG, postprandial blood glucose; TG, triglyceride; HDL-c, high-density lipoprotein-cholesterol; LDL-c, low-density lipoprotein-cholesterol; hs-CRP, high-sensitivity C-reactive protein; NT-proBNP, N-terminal prohormone of brain natriuretic peptide; Hcy, homocysteine.

The characteristics of the whole cohort based on the levels of CDRS and the presence of general obesity are described in Table 2. The individuals with CDRS $\geq 4$ and general obesity tended to have higher levels of BMI, WC, SBP, FINS, PBG, TG, and hypertension and lower levels of HDL-c than others $(P<0.05$ for all). Both groups were similar with regard to sex ratio and LDL-c levels $(P>0.05$ for all). The levels of DBP in the individuals with general obesity were higher than those of others $(P<0.05)$, but they were similar between the individuals with and without CDRS $\geq 4(P>0.05)$. The levels of serum FBG and history of high blood glucose in the individuals with $C D R S \geq 4$ were

Table 2 Baseline characteristics of entire population according to the levels of CDRS and the presence of general obesity

\begin{tabular}{|c|c|c|c|c|c|c|}
\hline Characteristics & $\begin{array}{l}\text { CDRS }<4 \\
(n=298)\end{array}$ & $\begin{array}{l}\text { CDRS } \geq 4 \\
(n=98)\end{array}$ & $P$-value & $\begin{array}{l}\text { Without general } \\
\text { obesity }(n=3 \mid 3)\end{array}$ & $\begin{array}{l}\text { With general } \\
\text { obesity }(n=83)\end{array}$ & $P$-value \\
\hline Age (years) & $64(57-70)$ & $68(63-72)$ & $<0.001$ & $66(59-72)$ & $63(57-69)$ & 0.083 \\
\hline Males (\%) & $161(54.0)$ & $50(51.0)$ & 0.605 & $167(53.4)$ & $44(53.0)$ & 0.956 \\
\hline BMI $\left(\mathrm{kg} / \mathrm{m}^{2}\right)$ & $24.68(22.50-26.90)$ & $26.82(24.88-28.31)$ & $<0.001$ & $24.35(22.22-26.08)$ & $29.88(28.72-30.93)$ & $<0.00 \mathrm{I}$ \\
\hline$W C(\mathrm{~cm})$ & $87.00(81.00-93.00)$ & $93.00(88.00-98.00)$ & $<0.001$ & $86.00(81.00-92.00)$ & $97(93-102)$ & $<0.00 \mathrm{I}$ \\
\hline Hypertension (\%) & $109(36.6)$ & $57(58.2)$ & $<0.001$ & $114(36.4)$ & $52(62.7)$ & $<0.00$ I \\
\hline $\mathrm{SBP}(\mathrm{mmHg})$ & $|3|(|20-| 42)$ & $139(126-150)$ & 0.001 & $13 \mid(\mid 20-143)$ & $140(130-150)$ & $<0.00$ I \\
\hline $\mathrm{DBP}(\mathrm{mmHg})$ & $78(70-85)$ & $80(70-90)$ & 0.203 & $77(70-84)$ & $84(76-91)$ & $<0.00 \mathrm{I}$ \\
\hline History of high blood glucose & $\mathrm{I}(0.3)$ & $19(19.4)$ & $<0.001$ & $17(5.4)$ & $3(3.6)$ & 0.696 \\
\hline $\mathrm{FBG}(\mathrm{mmol} / \mathrm{L})$ & $4.71(4.39-5.08)$ & $5.03(4.50-5.85)$ & $<0.001$ & $4.74(4.42-5.22)$ & $4.80(4.44-5.22)$ & 0.738 \\
\hline FINS (mlU/L) & $6.63(4.37-9.25)$ & $9.23(6.31-12.36)$ & $<0.001$ & $6.45(4.33-9.12)$ & $10.00(7.73-14.40)$ & $<0.001$ \\
\hline PBG (mmol/L) & $5.98(5.00-7.42)$ & $7.17(5.98-8.72)$ & $<0.00$ I & $6.12(5.09-7.69)$ & $7.04(5.55-8.38)$ & 0.009 \\
\hline $\mathrm{TG}(\mathrm{mmol} / \mathrm{L})$ & $1.31(0.99-1.66)$ & $1.93(I .40-2.6 \mathrm{I})$ & $<0.001$ & $1.34(1.00-1.76)$ & $1.66(1.35-2.91)$ & $<0.00 \mathrm{I}$ \\
\hline HDL-c (mmol/L) & $1.42(1.17-1.68)$ & $1.06(0.87-1.23)$ & $<0.001$ & $1.35(1.12-1.66)$ & $1.19(1.02-1.42)$ & $<0.00$ I \\
\hline LDL-c (mmol/L) & $2.82(2.36-3.30)$ & $2.86(2.45-3.37)$ & 0.298 & $2.80(2.36-3.35)$ & $3.00(2.52-3.40)$ & 0.164 \\
\hline hs-CRP (mg/dL) & $0.27(0.16-0.36)$ & $0.32(0.17-0.43)$ & 0.035 & $0.27(0.16-0.38)$ & $0.31(0.18-0.47)$ & 0.075 \\
\hline NT-proBNP $(\mathrm{pg} / \mathrm{mL})$ & 39.11 (15.95-76.98) & $49.35(21.74-116.60)$ & 0.009 & $4 I .40(17.25-78.53)$ & $42.35(17.50-95.33)$ & 0.674 \\
\hline Hcy $(\mu \mathrm{mol} / \mathrm{L})$ & $16.70(13.60-21.23)$ & $18.80(15.65-22.45)$ & 0.008 & $16.90(\mid 3.60-21.20)$ & $18.90(15.10-22.60)$ & 0.018 \\
\hline
\end{tabular}

Notes: Data presented as median (interquartile range) or $\mathrm{n}(\%)$.

Abbreviations: CDRS, Chinese diabetes risk score; BMI, body mass index; WC, waist circumference; SBP, systolic blood pressure; DBP, diastolic blood pressure; FBG, fasting blood glucose; FINS, fasting insulin; PBG, postprandial blood glucose; TG, triglyceride; HDL-c, high-density lipoprotein-cholesterol; LDL-c, low-density lipoprotein-cholesterol; hs-CRP, high-sensitivity C-reactive protein; NT-proBNP, N-terminal prohormone of brain natriuretic peptide; Hcy, homocysteine. 
Table 3 Correlation analyses for biomarkers in relation to the components of MetS and CDRS, MetS component numbers, CDRS, and HOMA-IR

\begin{tabular}{|c|c|c|c|c|c|c|}
\hline \multirow[t]{2}{*}{$\overline{\text { Characteristics }}$} & \multicolumn{2}{|c|}{ hs-CRP (mg/dL) } & \multicolumn{2}{|c|}{ NT-proBNP (pg/mL) } & \multicolumn{2}{|l|}{ Hcy ( $\mu \mathrm{mol} / \mathrm{L})$} \\
\hline & $\begin{array}{l}\text { Correlation } \\
\text { coefficient }\end{array}$ & $P$-value & $\begin{array}{l}\text { Correlation } \\
\text { coefficient }\end{array}$ & $P$-value & $\begin{array}{l}\text { Correlation } \\
\text { coefficient }\end{array}$ & $P$-value \\
\hline BMI $\left(\mathrm{kg} / \mathrm{m}^{2}\right)$ & 0.111 & 0.027 & -0.085 & 0.091 & 0.174 & 0.001 \\
\hline WC (cm) & 0.163 & 0.001 & -0.050 & 0.324 & 0.162 & 0.001 \\
\hline $\mathrm{SBP}(\mathrm{mmHg})$ & 0.097 & 0.053 & 0.114 & 0.023 & 0.167 & 0.001 \\
\hline $\mathrm{DBP}(\mathrm{mmHg})$ & 0.026 & 0.609 & -0.144 & 0.004 & 0.075 & 0.134 \\
\hline $\mathrm{FBG}(\mathrm{mmol} / \mathrm{L})$ & 0.153 & 0.002 & -0.070 & 0.164 & -0.170 & 0.001 \\
\hline TG (mmol/L) & 0.052 & 0.303 & -0.124 & 0.013 & 0.094 & 0.063 \\
\hline HDL-c (mmol/L) & -0.162 & 0.001 & 0.058 & 0.247 & -0.170 & 0.001 \\
\hline LDL-c (mmol/L) & 0.038 & 0.448 & 0.008 & 0.870 & 0.014 & 0.788 \\
\hline MetS component numbers & 0.133 & 0.008 & $0.04 I$ & 0.421 & 0.077 & 0.124 \\
\hline CDRS & 0.101 & 0.045 & 0.138 & 0.006 & 0.239 & $<0.001$ \\
\hline HOMA-IR & 0.096 & 0.057 & -0.158 & 0.002 & -0.013 & 0.791 \\
\hline
\end{tabular}

Abbreviations: MetS, metabolic syndrome; CDRS, Chinese diabetes risk score; HOMA-IR, homeostasis model assessment of insulin resistance; hs-CRP, high-sensitivity C-reactive protein; NT-proBNP, N-terminal prohormone of brain natriuretic peptide; Hcy, homocysteine; BMI, body mass index; WC, waist circumference; SBP, systolic blood pressure; DBP, diastolic blood pressure; FBG, fasting blood glucose; TG, triglyceride; HDL-c, high-density lipoprotein-cholesterol; LDL-c, low-density lipoproteincholesterol.

higher and more than those of others $(P<0.05$ for all), but they were similar between the individuals with and without general obesity $(P>0.05)$. Serum hs-CRP concentrations in the individuals with CDRS $\geq 4$ were higher than those of others $(P<0.05)$. Serum NT-proBNP concentrations in the individuals with CDRS $\geq 4$ were higher than those of others $(P<0.05)$, but they were similar between the individuals with and without general obesity $(P>0.05)$. Individuals who did not have CDRS $\geq 4$ and general obesity were likely to have higher serum Hcy concentrations compared with those who had CDRS $\geq 4$ and general obesity ( $P<0.05$ for all).

\section{Correlation analyses}

Correlation coefficients for biomarkers in relation to the components of MetS and CDRS, MetS component numbers, CDRS, and HOMA-IR are presented in Table 3. Serum hs-CRP concentrations were related to the levels of BMI, WC, FBG, HDL-c, MetS component numbers, and CDRS $(P<0.05$ for all). Serum NT-proBNP concentrations were correlated with the levels of SBP, DBP, TG, CDRS, and HOMA-IR $(P<0.05$ for all). Serum Hcy concentrations were linked to the levels of BMI, WC, SBP, FBG, HDL-c, and CDRS $(P<0.05$ for all). However, no other significant relationship was observed in the correlation analyses $(P>0.05$ for all).

\section{Receiver operating characteristic curve analyses}

Area under the curve values of biomarkers for identifying the components of MetS and CDRS, HOMA-IR, MetS, and CDRS are shown in Table 4. Serum hs-CRP concentrations were able to identify MetS, CDRS $\geq 4$, HDL-c $<0.9 / 1.0 \mathrm{mmol} / \mathrm{L}$, and HDL-c $<1.0 / 1.3 \mathrm{mmol} / \mathrm{L}$ $(P<0.05$ for all). Serum NT-proBNP concentrations were able to identify HOMA-IR $>1.5$, CDRS $\geq 4$, overweight, and $\mathrm{BP} \geq 140 / 90 \mathrm{mmHg}(P<0.05$ for all). Serum Hcy concentrations were able to identify $\mathrm{CDRS} \geq 4$, general obesity, overweight, and $\mathrm{BP} \geq 140 / 90 \mathrm{mmHg}(P<0.05$ for all).

\section{Logistic regression analyses}

The results from logistic analyses for biomarkers with the components of MetS and CDRS, HOMA-IR, MetS, and CDRS are displayed in Table 5. Serum hs-CRP concentrations were independently associated with MetS as well as HDL-c $<1.0 / 1.3 \mathrm{mmol} / \mathrm{L}$ and HDL-c $<0.9 / 1.0 \mathrm{mmol} / \mathrm{L}$ after adjustment shown in Table 5 ( $P<0.05$ for all). Serum NT-proBNP concentrations were independently associated with $\mathrm{BP} \geq 140 / 90 \mathrm{mmHg}$ after adjustment shown in Table $5(P<0.05)$. Serum Hcy concentrations were independently associated with CDRS $\geq 4$ after adjustment shown in Table $5(P<0.05)$. However, other associations for biomarkers did not reach statistical significance with adjustment $(P>0.05$ for all).

\section{Discussion}

MetS is a cluster of metabolic risk factors associated with an increased risk for developing diabetes and cardiovascular diseases. ${ }^{1}$ The prevalence of MetS and diabetes is increasing worldwide, thus creating an urgent need for evaluating biomarkers that can be used to further identify and treat individuals at greatest risk for MetS and diabetes and reduce 
Table 4 ROC curve analyses of biomarkers for identifying the components of MetS and CDRS, HOMA-IR, MetS, and CDRS

\begin{tabular}{|c|c|c|c|c|c|c|}
\hline \multirow[t]{2}{*}{ Characteristics } & \multicolumn{2}{|l|}{ hs-CRP (mg/dL) } & \multicolumn{2}{|c|}{ NT-proBNP (pg/mL) } & \multicolumn{2}{|l|}{$\mathrm{Hcy}(\mu \mathrm{mol} / \mathrm{L})$} \\
\hline & AUC $(95 \% \mathrm{Cl})$ & $P$-value & $\operatorname{AUC}(95 \% \mathrm{Cl})$ & $P$-value & AUC (95\% Cl) & $P$-value \\
\hline HOMA-IR > I.5 & $0.556(0.499-0.612)$ & 0.056 & $0.4 I 5(0.359-0.47 I)$ & 0.004 & $0.489(0.432-0.546)$ & 0.709 \\
\hline MetS & $0.625(0.566-0.684)$ & $<0.001$ & $0.523(0.462-0.584)$ & 0.462 & $0.542(0.48 I-0.603)$ & 0.174 \\
\hline CDRS $\geq 4$ & 0.57 I (0.502-0.640) & 0.036 & $0.588(0.522-0.653)$ & 0.009 & $0.590(0.527-0.652)$ & 0.008 \\
\hline General obesity & $0.564(0.49 \mid-0.636)$ & 0.075 & $0.515(0.444-0.586)$ & 0.674 & $0.584(0.515-0.653)$ & 0.018 \\
\hline Overweight & $0.545(0.486-0.603)$ & 0.142 & $0.426(0.368-0.485)$ & 0.015 & $0.577(0.519-0.635)$ & 0.012 \\
\hline Central obesity & $0.54 I(0.482-0.599)$ & 0.180 & $0.506(0.447-0.565)$ & 0.839 & $0.509(0.450-0.568)$ & 0.773 \\
\hline $\mathrm{BP} \geq 130 / 85 \mathrm{mmHg}$ & $0.540(0.482-0.598)$ & 0.190 & $0.545(0.487-0.604)$ & 0.136 & $0.556(0.497-0.614)$ & 0.066 \\
\hline $\mathrm{BP} \geq 140 / 90 \mathrm{mmHg}$ & $0.520(0.462-0.579)$ & 0.488 & $0.582(0.526-0.639)$ & 0.005 & $0.616(0.560-0.672)$ & $<0.001$ \\
\hline $\mathrm{TG} \geq 1.7 \mathrm{mmol} / \mathrm{L}$ & $0.525(0.462-0.588)$ & 0.418 & $0.455(0.394-0.517)$ & 0.153 & $0.530(0.469-0.590)$ & 0.344 \\
\hline $\mathrm{HDL}-\mathrm{c}<0.9 / 1.0 \mathrm{mmol} / \mathrm{L}$ & $0.626(0.535-0.717)$ & 0.008 & $0.505(0.4 \mathrm{I} 0-0.600)$ & 0.916 & $0.499(0.409-0.589)$ & 0.988 \\
\hline $\mathrm{HDL}-\mathrm{c}<\mathrm{I} .0 / 1.3 \mathrm{mmol} / \mathrm{L}$ & $0.592(0.53 \mathrm{I}-0.653)$ & 0.003 & $0.534(0.474-0.595)$ & $0.27 I$ & $0.509(0.447-0.570)$ & $0.78 I$ \\
\hline $\mathrm{FBG} \geq 5.6 \mathrm{mmol} / \mathrm{L}$ & $0.556(0.466-0.645)$ & 0.220 & $0.534(0.443-0.626)$ & 0.450 & $0.515(0.428-0.602)$ & 0.745 \\
\hline
\end{tabular}

Abbreviations: ROC, receiver operating characteristic; MetS, metabolic syndrome; CDRS, Chinese diabetes risk score; HOMA-IR, homeostasis model assessment of insulin resistance; hs-CRP, high-sensitivity C-reactive protein; NT-proBNP, N-terminal prohormone of brain natriuretic peptide; Hcy, homocysteine; BP, blood pressure; TG, triglyceride; HDL-c, high-density lipoprotein-cholesterol; FBG, fasting blood glucose; AUC, area under the curve; Cl, confidence interval.

morbidity and mortality associated with diabetes and cardiovascular diseases. ${ }^{2,3}$ CRP is a protein that is synthesized by liver and then secreted into circulation. It is a critical component of immune system and one of acute phase proteins that increase during systemic inflammation. Previous studies have revealed that serum hs-CRP levels were strongly related to MetS. ${ }^{4,5}$ On the contrary, other studies have discovered that serum hs-CRP levels were associated with MetS due to

Table 5 Logistic regression analyses for biomarkers with the components of MetS and CDRS, HOMA-IR, MetS, and CDRS

\begin{tabular}{|c|c|c|c|c|c|c|c|c|}
\hline \multirow{2}{*}{$\begin{array}{l}\text { Characteristics } \\
\text { (statistical indices) }\end{array}$} & \multicolumn{2}{|l|}{ MetS $^{a}$} & \multicolumn{2}{|l|}{ MetS } & \multicolumn{2}{|l|}{ MetS $^{b}$} & \multicolumn{2}{|l|}{ CDRS $\geq 4^{c}$} \\
\hline & HR (95\% Cl) & $\overline{P \text {-value }}$ & HR (95\% Cl) & $\overline{P \text {-value }}$ & HR (95\% Cl) & $P$-value & HR (95\% Cl) & $P$-value \\
\hline Hs-CRP (mg/dL) & $1.822(1.18 I-2.812)$ & 0.007 & $1.925(1.040-3.563)^{d}$ & 0.037 & 1.611 (0.799-3.249) & 0.183 & $1.558(0.979-2.479)$ & 0.061 \\
\hline NT-proBNP (pg/mL) & $0.833(0.526-1.320)$ & 0.437 & $\mathrm{I} .532(0.73 \mathrm{I}-3.212)^{\mathrm{e}}$ & 0.259 & $1.296(0.583-2.88 I)$ & 0.524 & $1.379(0.863-2.204)$ & 0.179 \\
\hline \multirow[t]{3}{*}{$\mathrm{Hcy}(\mu \mathrm{mol} / \mathrm{L})$} & $1.277(0.807-2.021)$ & 0.296 & $1.390(0.680-2.842)^{f}$ & 0.367 & $1.450(0.636-3.303)$ & 0.377 & $1.857(1.147-3.007)$ & 0.012 \\
\hline & \multicolumn{2}{|l|}{ CDRS $\geq 4$} & \multicolumn{2}{|l|}{ CDRS $\geq 4^{b}$} & \multicolumn{2}{|l|}{ HOMA-IR $>1.5^{8}$} & \multicolumn{2}{|l|}{ General obesity } \\
\hline & HR (95\% Cl) & $P$-value & HR (95\% Cl) & $P$-value & HR (95\% Cl) & $P$-value & HR (95\% Cl) & $P-v$ \\
\hline $\mathrm{Hs}-\mathrm{CRP}(\mathrm{mg} / \mathrm{dL})$ & $1.548(0.822-2.913)^{\mathrm{e}}$ & 0.176 & $1.598(0.784-3.255)$ & 0.197 & $1.569(0.997-2.472)$ & 0.052 & $1.172(0.685-2.005)$ & 0.563 \\
\hline NT-proBNP (pg/mL) & $1.450(0.694-3.029)^{d}$ & 0.323 & $1.350(0.614-2.968)$ & 0.455 & $0.737(0.45 \mathrm{I}-\mathrm{I} .205)$ & 0.224 & $1.505(0.830-2.731)$ & 0.179 \\
\hline \multirow[t]{3}{*}{ Hcy $(\mu \mathrm{mol} / \mathrm{L})$} & $1.704(0.779-3.730)^{f}$ & 0.182 & $1.500(0.675-3.336)$ & 0.320 & $0.67 \mid(0.409-1.102)$ & 0.115 & $1.603(0.905-2.84 I)$ & 0.106 \\
\hline & \multicolumn{2}{|l|}{ Overweight $^{h}$} & \multicolumn{2}{|l|}{ Central obesity } & \multicolumn{2}{|l|}{$B P \geq 130 / 85 \mathrm{mmHg}$} & \multicolumn{2}{|l|}{$\mathrm{BP} \geq 140 / 90 \mathrm{mmHg}$} \\
\hline & HR (95\% Cl) & $\overline{P \text {-value }}$ & HR (95\% CI) & $P$-value & HR (95\% Cl) & $P$-value & HR (95\% Cl) & $P$-value \\
\hline $\mathrm{Hs}-\mathrm{CRP}(\mathrm{mg} / \mathrm{dL})$ & $1.317(0.814-2.131)$ & 0.263 & $0.858(0.530-1.388)$ & 0.532 & $0.96 \mid(0.613-1.505)$ & $0.86 \mathrm{I}$ & $0.879(0.569-1.360)$ & 0.563 \\
\hline NT-proBNP (pg/mL) & $0.705(0.422-1.175)$ & 0.180 & $0.717(0.422-1.218)$ & 0.219 & I.57। (0.965-2.557) & 0.069 & $1.837(1.141-2.957)$ & 0.012 \\
\hline \multirow[t]{3}{*}{$\mathrm{Hcy}(\mu \mathrm{mol} / \mathrm{L})$} & $1.632(0.969-2.748)$ & 0.066 & $1.019(0.605-1.714)$ & 0.944 & 0.691 (0.420-1.137) & 0.146 & I. 105 (0.69I-I.765) & 0.678 \\
\hline & \multicolumn{2}{|l|}{$\overline{T G} \geq 1.7 \mathrm{mmol} / \mathrm{L}^{j}$} & \multicolumn{2}{|c|}{ HDL-c $<1.0 / 1.3 \mathrm{mmol} / \mathrm{L}^{\mathrm{k}}$} & \multicolumn{2}{|c|}{ HDL-c $<0.9 / 1.0 \mathrm{mmol} / \mathrm{L}^{\mathrm{k}}$} & \multicolumn{2}{|l|}{ FBG $\geq 5.6 \mathrm{mmol} / \mathrm{L}^{\mathrm{g}}$} \\
\hline & HR (95\% Cl) & $P$-value & HR (95\% Cl) & $P$-value & HR (95\% Cl) & $P$-value & HR (95\% Cl) & $P$-value \\
\hline $\mathrm{Hs}-\mathrm{CRP}(\mathrm{mg} / \mathrm{dL})$ & $0.869(0.518-1.458)$ & 0.595 & $1.778(1.034-3.059)$ & 0.037 & $2.598(1.155-5.840)$ & 0.021 & $1.280(0.66 \mathrm{I}-2.477)$ & 0.464 \\
\hline NT-proBNP (pg/mL) & $0.852(0.489-1.485)$ & 0.572 & I.I $54(0.64 \mathrm{I}-2.079)$ & 0.632 & $0.562(0.243-1.298)$ & 0.177 & $1.202(0.583-2.477)$ & 0.618 \\
\hline $\mathrm{Hcy}(\mu \mathrm{mol} / \mathrm{L})$ & I.27I (0.722-2.239) & 0.406 & $1.062(0.587-1.921)$ & 0.842 & $0.728(0.316-1.680)$ & 0.457 & $0.882(0.435-1.790)$ & 0.728 \\
\hline
\end{tabular}

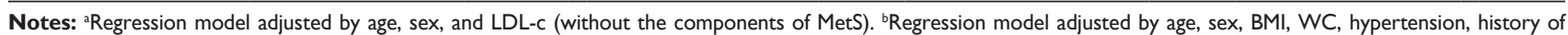
high blood glucose, SBP, DBP, FBG, PBG, TG, HDL-c, and LDL-c (with all variables, including the components of MetS and CDRS). ${ }^{\mathrm{C}}$ Regression model adjusted by sex and LDL-c (without the components of CDRS). ${ }^{\mathrm{d}}$ Regression model adjusted by age, sex, BMI, WC, hypertension, history of high blood glucose, SBP, DBP, FBG, PBG, TG, and LDL-C

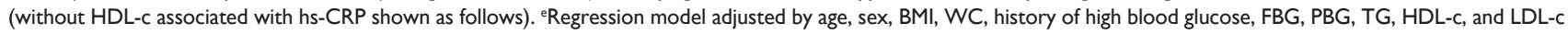
(without hypertension, SBP, and DBP associated with NT-proBNP shown as follows). fRegression model adjusted by age, sex, hypertension, history of high blood glucose, SBP,

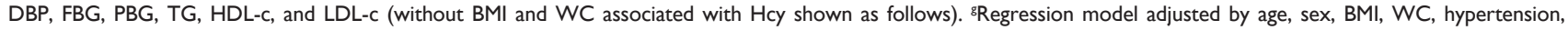
SBP, DBP, TG, HDL-c, and LDL-c (without history of high blood glucose, FBG, and PBG). "hegression model adjusted by age, sex, hypertension, history of high blood glucose, SBP, DBP, FBG, PBG, TG, HDL-c, and LDL-c (without BMI and WC). 'Regression model adjusted by age, sex, BMI, WC, history of high blood glucose, FBG, PBG, TG, HDL-c, and LDL-c (without hypertension, SBP and DBP). 'Regression model adjusted by age, sex, BMI, WC, hypertension, history of high blood glucose, SBP, DBP, FBG, PBG, HDL-c, and LDL-c (without TG). ${ }^{k}$ Regression model adjusted by age, sex, BMI, WC, hypertension, history of high blood glucose, SBP, DBP, FBG, PBG, TG, and LDL-c (without HDL-c). Abbreviations: MetS, metabolic syndrome; CDRS, Chinese diabetes risk score; HOMA-IR, homeostasis model assessment of insulin resistance; HR, hazard ratio; hs-CRP, high-sensitivity C-reactive protein; NT-proBNP, N-terminal prohormone of brain natriuretic peptide; Hcy, homocysteine; BP, blood pressure; TG, triglyceride; HDL-c, high-density lipoprotein-cholesterol; FBG, fasting blood glucose; BMI, body mass index; WC, waist circumference; SBP, systolic blood pressure; DBP, diastolic blood pressure; PBG, postprandial blood glucose; LDL-c, low-density lipoprotein-cholesterol; Cl, confidence interval. 
the influence of other variables. ${ }^{6}$ In the current study, serum hs-CRP levels were not only able to identify the presence of MetS but also independently associated with MetS after adjusting for all components of MetS and CDRS except serum HDL-c levels. Moreover, we found that serum HDL-c levels were the only component of MetS and CDRS that was independently associated with and identified by serum hs-CRP levels. Thus, serum HDL-c levels were the major determinant of the association between serum hs-CRP levels and MetS and even the key link between inflammation and MetS. It gave us some significant enlightenment on how to further understand the underlying mechanisms of inflammation and MetS, which can lead to better prevention and treatment of diabetes and cardiovascular diseases.

Serum hs-CRP levels have been reported to be a risk factor of diabetes and able to identify the development of diabetes. ${ }^{7}$ But studies from Lee et $\mathrm{al}^{8}$ have observed that there was no independent association between serum CRP levels and diabetes risk. In the current study, although serum hs-CRP levels had the ability to identify diabetes, serum hs-CRP levels had insignificant association with the risk of diabetes in fully adjusted analysis. Additionally, some studies have found a relationship between serum hs-CRP levels and IR, ${ }^{18}$ while other studies have revealed that serum hs-CRP levels were not closely related to IR. ${ }^{19}$ The current study indicated that serum hs-CRP levels had no chance to detect IR and were not related to IR after controlling for all components of MetS and CDRS. ${ }^{20,27}$

Conflicting data have existed on the associations of biomarkers, including serum NT-proBNP and Hcy levels, with IR, MetS, and diabetes risk. In some studies, serum NT-proBNP and Hcy levels have been significantly related to IR, MetS, and diabetes risk. ${ }^{9-12,21}$ However, there has been no relationship of serum NT-proBNP and Hcy levels with IR, MetS, and diabetes risk in other studies. ${ }^{13,14,22}$ The current study showed that despite the identification of one or more of IR, MetS, and diabetes risk by serum NT-proBNP and Hcy levels, there was no independent association of serum NT-proBNP and Hcy levels with IR, MetS, and diabetes risk after full adjustment covering all components of MetS and CDRS.

Previous studies have reported a positive association between serum NT-proBNP levels and BP. ${ }^{28}$ In conformity with these data, we found that BP was not only able to be detected by serum NT-proBNP levels but also the only component of MetS and CDRS independently associated with serum NT-proBNP levels after eliminating the influence of all other components of MetS and CDRS. The relationships of serum NT-proBNP levels with other components of MetS and CDRS have been described recently, ${ }^{29-31}$ but they lost independence after full adjustment in the current study. Meanwhile, although serum Hcy levels were able to identify several components of MetS, they were not independently related to them in the current study, which was in accordance with the results from previous studies. ${ }^{32,33}$

\section{Conclusion}

The current study performed deep analyses of the associations of biomarkers, including serum hs-CRP, NT-proBNP, and Hcy levels, with IR, MetS, and diabetes risk in non-diabetic Chinese community-dwelling middle-aged and elderly population, which possess significant clinical implications. In the current study, serum HDL-c levels were the major determinant of the association between serum hs-CRP levels and MetS and the key link between inflammation and MetS. There was no other association of these biomarkers with IR, MetS, and diabetes risk after full adjustment.

\section{Acknowledgments}

This study was supported by grants from National Key Basic Research Project (2012CB517503 and 2013CB530804), Health Special Scientific Research Subject of Chinese People's Liberation Army (12BLZ34), and Clinical Scientific Research Project of Chinese People's Liberation Army General Hospital (2012FC-TSYS1021). We are grateful to all study participants for their participation in the study.

\section{Disclosure}

The authors report no conflicts of interest in this work.

\section{References}

1. Sattar N, McConnachie A, Shaper AG, et al. Can metabolic syndrome usefully predict cardiovascular disease and diabetes? Outcome data from two prospective studies. Lancet. 2008;371(9628):1927-1935.

2. Ilanne-Parikka P, Eriksson JG, Lindstrom J, et al; Finnish Diabetes Prevention Study Group. Effect of lifestyle intervention on the occurrence of metabolic syndrome and its components in the Finnish Diabetes Prevention Study. Diabetes Care. 2008;31(4):805-807.

3. Kannel WB, McGee DL. Diabetes and cardiovascular disease: the Framingham study. JAMA. 1979;241(19):2035-2038.

4. Zuliani G, Volpato S, Galvani M, et al. Elevated C-reactive protein levels and metabolic syndrome in the elderly: the role of central obesity data from the InChianti study. Atherosclerosis. 2009;203(2):626-632.

5. Mahajan A, Jaiswal A, Tabassum R, et al. Elevated levels of C-reactive protein as a risk factor for metabolic syndrome in Indians. Atherosclerosis. 2012;220(1):275-281.

6. den Engelsen C, Koekkoek PS, Gorter KJ, van den Donk M, Salomé PL, Rutten GE. High-sensitivity C-reactive protein to detect metabolic syndrome in a centrally obese population: a cross-sectional analysis. Cardiovasc Diabetol. 2012;11:25.

7. Perticone F, Maio R, Sciacqua A, et al. Endothelial dysfunction and $\mathrm{C}$-reactive protein are risk factors for diabetes in essential hypertension. Diabetes. 2008;57(1):167-171. 
8. Lee CC, Adler AI, Sandhu MS, et al. Association of C-reactive protein with type 2 diabetes: prospective analysis and meta-analysis. Diabetologia. 2009;52(6):1040-1047.

9. Choi HK, Ford ES. Prevalence of the metabolic syndrome in individuals with hyperuricemia. Am J Med. 2007;120(5):442-447.

10. Vayá A, Rivera L, Hernández-Mijares A, et al. Homocysteine levels in morbidly obese patients: its association with waist circumference and insulin resistance. Clin Hemorheol Microcirc. 2012;52(1):49-56.

11. Aboul Ella NA, Shehab DI, Ismail MA, Maksoud AA. Prevalence of metabolic syndrome and insulin resistance among Egyptian adolescents 10 to 18 years of age. J Clin Lipidol. 2010;4(3):185-195.

12. Melander O, Frandsen E, Magnusson M, Grubb A, Jovinge S, Groop L. Nt-proANP in plasma, a marker of salt sensitivity, is reduced in type 2 diabetes patients. J Intern Med. 2005;257(3):281-288.

13. Lee JG, Lee S, Kim YJ, et al. Multiple biomarkers and their relative contributions to identifying metabolic syndrome. Clin Chim Acta. 2009; 408(1-2):50-55.

14. Garcin JM, Cremades S, Garcia-Hejl C, et al. Is hyperhomocysteinemia an additional risk factor of the metabolic syndrome? Metab Syndr Relat Disord. 2006;4(3):185-195.

15. Yang $\mathrm{T}, \mathrm{Chu} \mathrm{CH}$, Bai $\mathrm{CH}$, et al. Uric acid level as a risk marker for metabolic syndrome: a Chinese cohort study. Atherosclerosis. 2012;220(2):525-531.

16. Ye X, Yu Z, Li H, Franco OH, Liu Y, Lin X. Distributions of C-reactive protein and its association with metabolic syndrome in middle-aged and older Chinese people. J Am Coll Cardiol. 2007;49(17):1798-1805.

17. Alberti KG, Eckel RH, Grundy SM, et al; International Diabetes Federation Task Force on Epidemiology and Prevention; National Heart, Lung, and Blood Institute; American Heart Association; World Heart Federation; International Atherosclerosis Society; International Association for the Study of Obesity. Harmonizing the metabolic syndrome: a joint interim statement of the International Diabetes Federation Task Force on Epidemiology and Prevention; National Heart, Lung, and Blood Institute; American Heart Association; World Heart Federation; International Atherosclerosis Society; and International Association for the Study of Obesity. Circulation. 2009;120(16):1640-1645.

18. Meng YX, Ford ES, Li C, et al. Association of C-reactive protein with surrogate measures of insulin resistance among nondiabetic US from National Health and Nutrition Examination Survey 1999-2002. Clin Chem. 2007;53(12):2152-2159.

19. Howard BV, Best L, Comuzzie A, et al. C-Reactive protein, insulin resistance, and metabolic syndrome in a population with a high burden of subclinical infection: insights from the Genetics of Coronary Artery Disease in Alaska Natives (GOCADAN) study. Diabetes Care. 2008; 31(12):2312-2314.

20. Yudkin JS, Stehouwer CD, Emeis JJ, Coppack SW. C-reactive protein in healthy subjects: associations with obesity, insulin resistance, and endothelial dysfunction: a potential role for cytokines originating from adipose tissue? Arterioscler Thromb Vasc Biol. 1999;19(4):972-978.
21. Ybarra J, Planas F, Navarro-López F, et al. Association between sleep-disordered breathing, aminoterminal pro-brain natriuretic peptide (NT-proBNP) levels and insulin resistance in morbidly obese young women. Eur J Intern Med. 2009;20(2):174-181.

22. Sheu WH, Lee WJ, Chen YT. Plasma homocysteine concentrations and insulin sensitivity in hypertensive subjects. Am J Hypertens. 2000; 13(1 pt 1):14-20.

23. Wallace TM, Levy JC, Matthews DR. Use and abuse of HOMA modeling. Diabetes Care. 2004;27(6):1487-1495.

24. Alberti KG, Zimmet P, Shaw J; IDF Epidemiology Task Force Consensus Group. The metabolic syndrome: a new worldwide definition. Lancet. 2005;366(9491):1059-1062.

25. Chen C, Lu FC; Department of Disease Control Ministry of Health, PR China. The guidelines for prevention and control of overweight and obesity in Chinese adults. Biomed Environ Sci. 2004;17(suppl):1-36.

26. Liu M, Pan C, Jin M. A Chinese diabetes risk score for screening of undiagnosed diabetes and abnormal tolerance. Diabetes Technol Ther. 2011;13(5):501-507.

27. Hak AE, Pols HA, Stehouwer CD, et al. Markers of inflammation and cellular adhesion molecules in relation to insulin resistance in nondiabetic elderly: the Rotterdam Study. J Clin Endocrinol Metab. 2001;86(9):4398-4405.

28. Buckley MG, Markandu ND, Miller MA, Sagnella GA, MacGregor GA. Plasma concentrations and comparisons of brain and atrial natriuretic peptide in normal subjects and in patients with essential hypertension. J Hum Hypertens. 1993;7(3):245-250.

29. Mehra MR, Uber PA, Park MH, et al. Obesity and suppressed B-type natriuretic peptide levels in heart failure. J Am Coll Cardiol. 2004; 43(9):1590-1595.

30. Lafontan M, Moro C, Sengenes C, Galitzky J, Crampes F, Berlan M. An unsuspected metabolic role for atrial natriuretic peptides: the control of lipolysis, lipid mobilization, and systemic nonesterified fatty acids levels in humans. Arterioscler Thromb Vasc Biol. 2005;25(10):2032-2042.

31. Krauser DG, Lloyd-Jones DM, Chae CU, et al. Effect of body mass index on natriuretic peptide levels in patients with acute congestive heart failure: a ProBNP Investigation of Dyspnea in the Emergency Department (PRIDE) substudy. Am Heart J. 2005;149(4):744-750.

32. Budak N, Yazici C, Oztürk A, Bayram F, Mazicioğlu MM, Kurtoglu S. Is plasma homocysteine level associated with metabolic syndrome components in adolescents? Metab Syndr Relat Disord. 2009;7(4): 357-362.

33. Guven A, Inanc F, Kilinc M, Ekerbicer H. Plasma homocysteine and lipoprotein (a) levels in Turkish patients with metabolic syndrome. Heart Vessels. 2005;20(6):290-295.
Clinical Interventions in Aging

\section{Publish your work in this journal}

Clinical Interventions in Aging is an international, peer-reviewed journal focusing on evidence-based reports on the value or lack thereof of treatments intended to prevent or delay the onset of maladaptive correlates of aging in human beings. This journal is indexed on PubMed Central, MedLine,

\section{Dovepress}

CAS, Scopus and the Elsevier Bibliographic databases. The manuscript management system is completely online and includes a very quick and fair peer-review system, which is all easy to use. Visit http://www.dovepress. com/testimonials.php to read real quotes from published authors. 